\title{
An Innovative 3 Dimensional Model of Middle Ear
}

\author{
Shilpi Gupta Dixit ${ }^{l}$, Abhinav Dixit ${ }^{2}$, Pushpa Potaliyal, Surajit Ghatak ${ }^{l}$ \\ ${ }^{1}$ Department of Anatomy, ${ }^{2}$ Department of Physiology \\ All India Institute of Medical Sciences, Jodhpur.
}

\begin{abstract}
Background: Physical models are particularly useful in demonstrating complex topics in anatomy or those ones that are difficult to access when seen in the textbook or cadaver. One such topic is middle ear. Aim of the present study was to introduce a multicolored cardboard model of middle ear to provide ease in understanding of its anatomical structure.
\end{abstract}

Methods: The participants were $2^{\text {nd }}$ semester medical undergraduate class of students. They were exposed to a cuboidal multicolored model (made from cardboard box) with 6 walls that could be opened to see the details of structures related to them. Student feedback was taken through a structured Questionnaire based on Likert Scale (5 to 1).

Results: More than $80 \%$ of students felt that this model was a good tool for visualizing complex anatomy of middle ear in small groups and it reduced the time needed for selfstudy. This model provided multifaceted feedback with active participation from students. A low fidelity middle ear model proved to be a practical low cost tool for use in both didactic and small group teaching.

Conclusion: Low fidelity models continue to have a place in anatomy and can be integrated in the current curriculum.

Keywords: Middle ear, 3 dimensional, teaching methodologies, gross anatomy education.

Correspondence : Dr. Shilpi Gupta Dixit, Associate Professor, Department of Anatomy, All India Institute of Medical Sciences, Basni Phase II, Jodhpur, Rajasthan342005. Mob.no: 0-8003996888,E-mail : shilpidr@gmail.com. 


\section{INTRODUCTION}

Since historic times, teaching and learning anatomy has been an integral part of medical education. The course content of Anatomy is vast and requires in-depth knowledge. The study of anatomy is generally related to identifying various structures along with their spatial relationships with respect to each other. The primary goal of study of human gross anatomy as well as physiology is anatomical reasoning with anatomical and physiological explanations of normal and abnormal functioning of the body, clinical signs and pathogenesis of various diseases as well as of procedures for clinical examination and surgeries.

A strong foundation of understanding anatomy requires appreciation of complex 3D spatial relationships and conceptual $3 \mathrm{D}$ visualization skills. There has been a continuing debate about the best way of teaching anatomy. For centuries, the classical way of anatomy education was cadaveric dissection, which has been a gold standard due to its engagement of multiple senses of students (1). There are alternative methods like computer aided learning with construction of human body in virtual 3 dimensional space generated by digital computers and low fidelity models which show spatial relationships between structures of human body $(2,3)$.

The morphology of the middle ear is difficult to appreciate during human dissection because of its complex shape and intricately arranged structures in 3D configuration.

The aim of the present study was to introduce a multicolored cardboard model of middle ear to improve the concept of 3D relationship of various structures in it.

The students were encouraged to participate in the practical session and were allowed to manipulate the model with their hands. Student feedback was taken through a structured questionnaire based on Likert scale (from 5 to 1 ).

\section{Materials and Methods:}

The study involved 2nd Semester medical students $(n=78)$. The students were divided into random groups and exposed to a 3D model of middle ear under the supervision of facilitators.

A cuboidal cardboard box was converted into a multicolored model with 6 faces corresponding to roof, floor, medial, lateral, anterior and posterior (Fig. $1,2)$. The walls could be opened to see the details of structures related to them (Fig. $3)$. Anatomical color code was followed i.e. arteries were in red, veins in blue, nerves in yellow and muscles in brown. The legends of the model were separately printed as a small manual. The students were encouraged to actively participate in the demonstration of the model.

The contents of the middle ear i.e. the ear ossicles were not demonstrated in the model. 


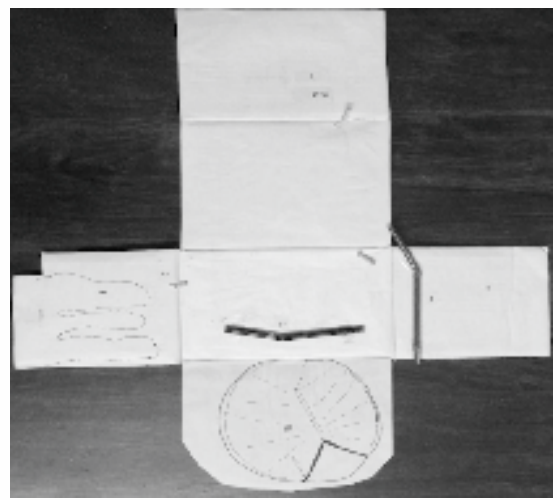

Fig. 1: Model of middle ear opened from outer aspect

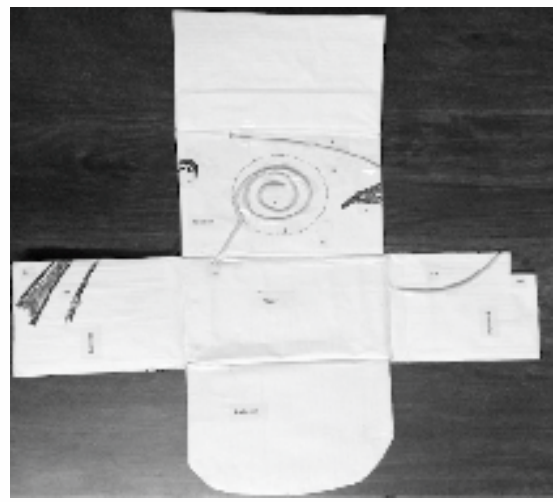

Fig. 2: Model of middle ear opened from inner aspect

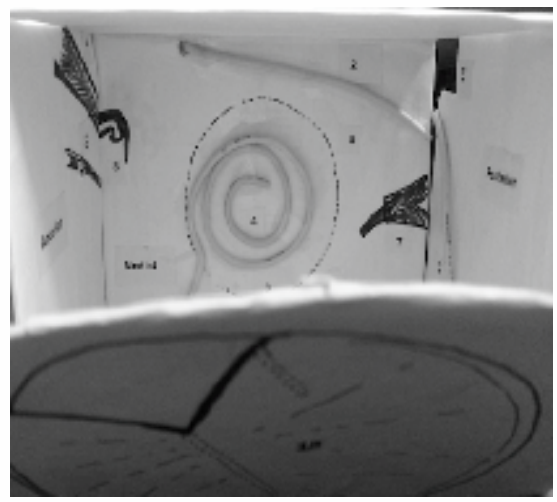

Fig. 3: Model of middle ear with closed walls
At the end of the session, the students were asked to record advantages of this external representation of middle ear under the following headings:

1. Dimensions

2. Number of structures included in the model

3. Spatial relationships between structures

4. Size of structures in comparison to normal size

5. Shape and details of color, pattern of structures

A student feedback was taken through a structured questionnaire and rated on a score of 5-1 based on Likert scale (Table 1) was taken at the end of the session.

\section{Results:}

The physical model of middle ear was well perceived by the students and was assessed in the following aspects by the authors:

1. Dimensionality: The model was 3 dimensional with a close resemblance to the actual middle ear having 6 walls. This was better understood by the students as compared to the computer generated virtual 2D model with just visual clues to indicate depth.

2. Number of structures: 18 out of 20 structures were represented in the model that was in close resemblance to the actual structure.

3. The spatial relationships between 
Table1: Student feedback questionnaire with responses (in \%)

\begin{tabular}{|c|c|c|c|c|c|c|}
\hline $\begin{array}{l}\text { S. } \\
\text { No. }\end{array}$ & Questions & $\begin{array}{l}\text { Strongly } \\
\text { Agree } \\
\text { (5) }\end{array}$ & $\begin{array}{l}\text { Agree } \\
\text { (4) }\end{array}$ & $\begin{array}{l}\text { Neutral } \\
\text { (3) }\end{array}$ & $\begin{array}{l}\text { Disagree } \\
\text { (2) }\end{array}$ & $\begin{array}{l}\text { Strongly } \\
\text { Disagree } \\
\text { (1) }\end{array}$ \\
\hline 1. & $\begin{array}{l}\text { I prefer to use this model in a } \\
\text { group session. }\end{array}$ & 47.4 & 44.9 & 7.7 & 0 & 0 \\
\hline 2. & $\begin{array}{l}\text { I prefer learning anatomy of middle ear by } \\
\text { using this } 3 \mathrm{D} \text { model }\end{array}$ & 65.4 & 28.2 & 2.6 & 2.6 & 1.3 \\
\hline 3. & $\begin{array}{l}\text { This } 3 \mathrm{D} \text { model demonstrates the middle ear } \\
\text { anatomy in a way that is easier to visualize }\end{array}$ & 47.4 & 41.0 & 7.7 & 3.8 & 0 \\
\hline 4. & $\begin{array}{l}\text { If I am learning the anatomy of middle ear I } \\
\text { want to have this resource available to me }\end{array}$ & 29.5 & 51.3 & 15.4 & 0 & 0 \\
\hline 5. & It is a useful tool to students & 50.0 & 44.9 & 5.1 & 14.1 & 0 \\
\hline 6. & $\begin{array}{l}\text { This physical model is better as a tool than } \\
\text { any } 3 \mathrm{D} \text { software }\end{array}$ & 34.6 & 26.9 & 21.8 & 0 & 2.6 \\
\hline 7. & $\begin{array}{l}\text { Helps in understanding/visualizing the } \\
\text { anatomy of middle ear written in text books }\end{array}$ & 52.6 & 42.3 & 5.1 & 0 & 0 \\
\hline 8. & $\begin{array}{l}\text { Small group learning is better than didactic } \\
\text { lectures }\end{array}$ & 53.8 & 30.8 & 15.4 & 0 & 0 \\
\hline 9. & It reduced the time needed for self-study & 33.3 & 50.0 & 12.8 & 0 & 3.8 \\
\hline 10. & $\begin{array}{l}\text { It had positive impact on my attitude towards } \\
\text { learning }\end{array}$ & 39.7 & 42.3 & 16.7 & 0 & 1.3 \\
\hline
\end{tabular}

various structures in the model were clearly indicated which also included the relation of various structures with roof, floor, anterior, posterior, medial and lateral walls of middle ear cavity.

4. Absolute and relative size of structures: The size of structures were amplified as the middle ear cavity is very complex and cannot be comprehended in its absolute size.

5. The color and pattern of various structures as well as blood vessels was maintained closed to normal as much as possible.
A student feedback was taken through a structured questionnaire (Table 1). The feedback was expressed in percentage for each question (Chart 1).

\section{Discussion:}

More than $80 \%$ of students felt that the 3D model was a good and useful learning tool for demonstration of middle e a r anatomy and helped in understanding/visualizing the anatomy of middle ear in textbooks. They also felt that it had a positive impact on their attitude towards learning. A large number of students also felt that small group learning 


\section{Chart 1: Student feedback response (in \%)}

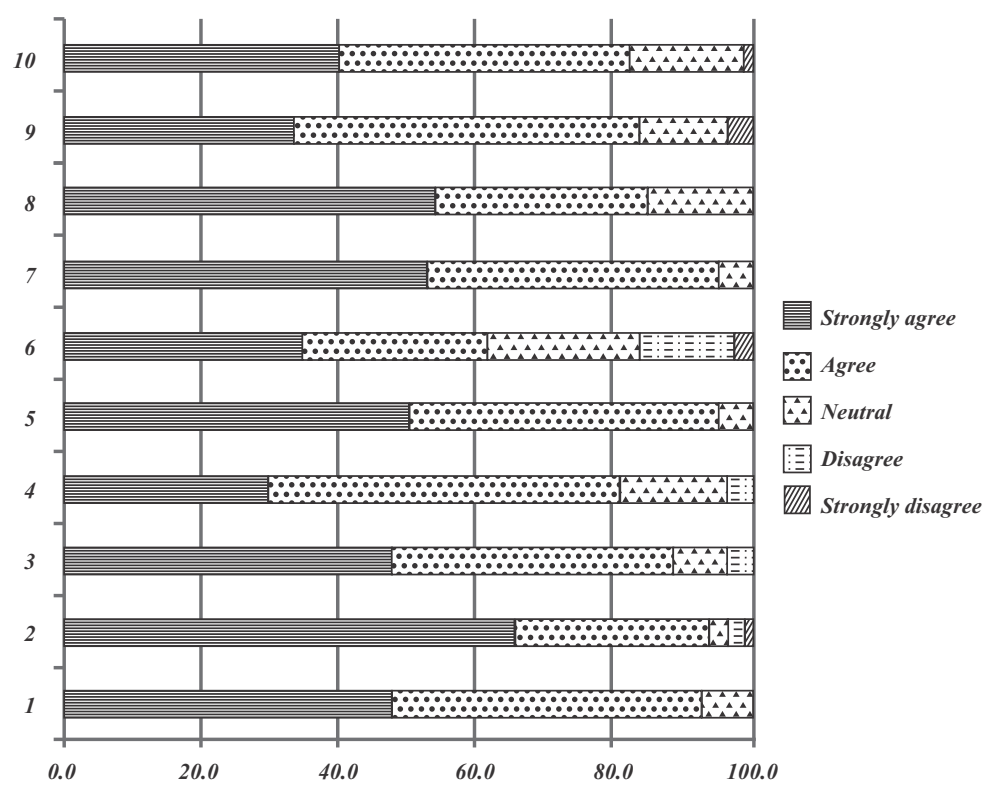

was better than didactic lectures and that these kind of models reduced time required for self-study (Table 1, Chart 1).

Anatomy is a vast field and an essential foundation for the study of medicine in diagnosis and therapy (1). The study of anatomy mainly involves identification of structures and forming concepts through 3D visualization skills. Dissection and prosections are generally considered to be the gold standard of anatomy education (1). Various advantages of using dissection as a learning tool include conceptualization of multidimensional aspects of human body, tactile manipulation of tissues, acquiring practical skills for dissection, appreciation of anatomical variations, ethical and moral issues arising from obtaining and contact with cadavers.
However, there has been a decline in teaching through dissection due to decrease in the availability of cadavers and also moral and ethical issues surrounding their use. Medical institutions across the globe are introducing various alternative methods of teaching anatomy $(1,4,5) .2 \mathrm{D}$ representations like $2 \mathrm{D}$ images, textbooks, chalk drawings, cause an increase in the cognitive overload on students (6).

Interest in the development and use of new educational tools has grown due to increase in the demand of new products for teaching. Anatomy model is a construct that is similar to the structure of any part of human body and can be used in learning and teaching students. It can be physical or digital (virtual 3D computer 
image). Physical models can be used to supplement current teaching methods and are particularly useful in demonstrating complex topics or those ones that are difficult to access when seen in the textbook or cadaver (7). One such topic is middle ear. Classical textbooks illustrate its morphology using drawings and pictures with different viewing angles and are difficult to comprehend. Physical models are good 3 dimensional external representations of human body. We assessed various aspects of the physical model of middle ear in a way that was similar to the study done by Chan and Cheng (8).

Studies have reported that physical models had visible visuospatial advantages over textbooks as well as $3 \mathrm{D}$ computer models both objectively and subjectively (6). Khot et al. in their study came to a conclusion that a group of students who used 3D plastic model did better than the groups using either 2D photographs or 3D computer based virtual images (9).

Although the model of middle ear made by the authors was low fidelity one, these models have several advantages over others in education. They serve as good memory aids as they can be easily remembered because they simplify complex spatial relationships of regions of the body, which are difficult to comprehend. Another advantage is reduction in cognitive overload by reducing the amount of information needed by them to attain their desired educational goals. These models arouse student's enthusiasm and participation.

Krontiris \& Litowitz have shown that hand held "manipulatives" improve critical thinking of undergraduate students (10). These models require minimal resources to make and reproduce by using inexpensive and easily available materials. These low fidelity models require proper instructions by the teacher to establish correspondence of the model to the structures of the body.

Thus, low fidelity models that are external representations of various structures of the body, which may not exactly correspond to these structures and require proper instructions for study by students, they still have numerous advantages over other alternative methods of education. Student manipulation of these models was encouraged, as they were easily reproducible even if damaged which is in contrast to expensive 3D virtual images and other life like physical models.

\section{Limitations of the study:}

The present study has few limitations. The student group on which the study was done was small in number and they were given the model after the didactic lecture on middle ear was taken.

\section{Conclusion:}

A low fidelity middle ear model proved to be a practical low cost tool for use in didactic and small group teaching. These models continue to have a place in 
anatomy and can be integrated in the current curriculum as by making these models, the students get a better spatial orientation and understanding of the body.

\section{REFERENCES:}

1. Sugand K, Abrahams P, Khurana A (2010). The anatomy of anatomy: A review of its modernization. Anat SciEduc 3: 83-93.

2. Rosse C (1995). The potential of computerized representations of anatomy in the training of health care providers. Acad Med 70:499505 .

3. Nguyen N, Wilson TD (2009). A head in virtual reality: Development of a dynamic head and neck model. Anat SciEduc 2:294-301.

4. Parker LM (2002). What's wrong with the dead body? Use of human cadaver in medical education. Med J Aust 176:74-76.

5. Nicholson DT, Chalk C, Funnell WR, Daniel SJ (2006). Can virtual reality improve anatomy education? A randomized controlled study of a computer-generated three- dimensional anatomical ear model. MedEduc 40:1081-1087.

6. Garg A, Norman GR, Spero L, Maheshwari P (1999). Do virtual computer models hinder anatomy learning? Acad Med 74:S87-S89.

7. Tam MDBS, Hart AR, Williams S, Heylings D, Leinster S (2009). Is learning anatomy facilitated by computer-aided learning? A review of literature. Med Teach 31:e393e396.

8. Chan LK, Cheng MMW (2011). An analysis of the educational value of low-fidelity anatomy models as external representations. Anat Sci Educ 4:256-263.

9. Khot Z, Quinlan K, Norman GR, Wainman B (2013). The relative effectiveness of computer based and traditional resources for education in anatomy. Anat Sci Educ 6:211215.

10. Krontiris-Litowitz J (2003). Using manipulatives to improve learning i n the undergraduate neurophysiology curriculum. $A d v$ Physiol Educ 27:109-119. 